\title{
Felling do empreendedor e marketing estratégico: influências em uma PME
}

Juliana De Oliveira Becheri ${ }^{1}$

Lauriene Teixeira Santos ${ }^{2}$

Izadora Ribeiro E Garcia De Oliveira ${ }^{2}$

Paulo Henrique Montagnana Vicente Leme ${ }^{1}$

${ }^{1}$ Universidade Federal de Lavras

2 Universidade Federal de Lavras / Departamento de Administração e Economia 


\section{Felling do empreendedor e marketing estratégico: influências em uma PME}

Resumo: Considerando que, muitas das vezes, nas micro, pequenas e médias empresas o hábito de desenvolver estratégias de marketing não está instaurado e, que na própria academia tem-se discutido que o papel funcional do marketing estratégico tem sido negligenciado, o objetivo geral do presente artigo é analisar como uma PME graduada em um programa de incubação de empresas utiliza o marketing estratégico para se estabelecer e crescer em seu mercado de atuação. Para tanto, a metodologia utilizada foi o estudo de caso da empresa Inova GS aliada à técnica de análise de conteúdo sob os preceitos de Bardin. Como resultado, obteve-se que os maiores benefícios do emprego do marketing estratégico pela empresa estão em gerar reconhecimento no mercado para marca. Ademais, a Inova GS considera que seguir à risca o planejamento estratégico de marketing, acarretaria perda de competitividade, visto que impede a resposta de forma adequada aos desafios apresentados pelo mercado.

Palavras-chave: Estratégias de marketing. Estratégias Emergentes. Aprendizagem organizacional. Empresa incubada.

\section{$1 \quad$ Introdução}

Nas micro, pequenas e médias empresas (MPMEs) o hábito de desenvolver uma estratégia de marketing, muita das vezes, não está instaurado. Apesar disso, juntas essas empresas emergem como um ator dominante nas economias nacionais (R. SRINVASAN et al, 2015). No Brasil, tais empresas correspondem 98,5\% dos negócios formais, empregam $54,5 \%$ da população, participam de $27 \%$ do PIB e, ainda são consideradas estratégicas ao proporcionar que os índices de inovação e competitividade sejam melhorados (BANCO DO NORDESTE, 2018).

Embora tais empresas sejam importantes para a economia até mesmo de nações desenvolvidas como, por exemplo, a dos Estados Unidos, muitas delas sofrem com diversos problemas mercadológicos, financeiro/econômico e gerenciais, que podem levá-las a morte (FERREIRA et al, 2018). Assim, com o intuito de reduzir essas instabilidades, os empreendedores que criam negócios sob a forma de MPMEs têm procurado se instalar em incubadoras de empresas (BROZE et al, 2019).

As MPMEs incubadas recebem suporte para o gerenciamento de todo seu empreendimento, que as ajuda a se desenvolver e consolidar o seu negócio no mercado. Este suporte oferecido pelas incubadoras diminui as possibilidades de mortalidade dessas empresas e, ainda contribui para alavancar seu potencial inovador e mercadológico (ANPROTEC, 2012).

Neste sentido, através das consultorias ofertadas pelas incubadoras, espera-se que as MPMEs incubadas tenham uma predisposição maior em adotar estratégias, especialmente voltadas à área de marketing. Isso porque, os clientes estão cada vez mais bem informados sobre os produtos e serviços, e estes têm se tornado mais criteriosos em relação as suas preferências, realizando reflexões sobre as suas decisões de consumo (SILVA, VIEIRA, 2012). Ainda relacionado ao aumento das informações, as empresas também tem ganhado a capacidade de especular o futuro com razoável precisão, através dos vários sistemas de gerenciamento e da tecnologia da informação (SRINVASAN et al, 2015). 
Por outro lado, Alves (2016) afirma que o papel funcional do marketing estratégico tem sido negligenciado pela própria área de marketing. Assim sendo, estudos que objetivem preencher essa lacuna representam uma oportunidade para que sejam compreendidas questões importantes envolvendo a gestão estratégica. Em paralelo, pode-se afirmar que grande parte das MPMEs em países em desenvolvimento, igual às MPMEs indianas, desconhecem o poder dessas estruturas estratégicas ou não apresentam inclinação para utilizar o marketing estratégico (SRINVASAN et al, 2015).

Tendo em vista o que se pontuou nesta introdução, este artigo tem como objetivo analisar como uma PME graduada em um programa de incubação de empresas utiliza o marketing estratégico para se estabelecer e, ao mesmo tempo, crescer em seu mercado de atuação. Especificamente, objetiva-se: (i) identificar as práticas de marketing estratégicas; (ii) compreender como as estratégias deliberadas e emergentes se dão no contexto da organização; (iii) entender a relação entre a aprendizagem organizacional e o felling do empreendedor com o marketing estratégico adotado e; (iv) entender como as práticas estratégicas de marketing impactam a cultura organizacional.

Para tanto, a unidade de análise deste estudo caso é a empresa Inova GS, uma MPME graduada em um programa de incubação de empresa, que tem como foco principal a oferta de soluções tecnológicas para interação entre instituições de ensino, estudantes e empresas, que tem recebido destaque no InovAtiva Brasil.

As justificativas para este trabalho se estendem na importância das MPMEs para economia do país, bem como, pela falta de literatura a respeito desta temática, englobando as práticas e a gestão do marketing estratégico nessas organizações. Justifica-se ainda a realização desta pesquisa, pela contribuição para as discussões a respeito do papel da incubadora no auxílio e incentivo de formulações estratégicas pelas MPMEs.

\section{$2 \quad$ Referencial Teórico}

O presente tópico contempla o que tem sido discutido acerca do marketing estratégico e das estratégias deliberadas e emergentes na academia.

\subsection{Marketing Estratégico}

Tendo em vista a iminência da quarta revolução industrial, como também, os avanços relacionados às tecnologias da informação e comunicação, biotecnologia, inteligência artificial, dentre outros avanços científicos/tecnológicos, o marketing estratégico é de particular interesse para as organizações que objetivam obter vantagem competitiva e/ou mesmo se manter em no mercado, onde a presença digital assume importância na efetivação das vendas e na construção da cartela de clientes.

Segundo Mckenna (2000) a tecnologia além de modificar o mercado, tem contribuído para modificar as atividades de marketing, como tem sido observado nas grandes empresas, onde a maioria das modificações tem sido de reação e não de previsão. $\mathrm{O}$ autor ainda afirma que a imagem das organizações vai se originar mais de experiências interativas (que necessitarão ser constantemente renovadas). Além disso, haverá convergência entre empresas de softwares e agências de publicidades, isso porque, cada vez mais o marketing será encarregado de captar informações para melhor entender os consumidores, e assim, assegura que a empresa continue competitiva. 
Esta última questão é defendida por Okada e Souza (2011), que afirmam ser necessário um planejamento estratégico que integre Marketing e TI para o desenvolvimento de projetos de SEM (Search Engine Marketing) e SEO (Search Engine Otimization). Ademais, como práticas de marketing digital têm-se as mídias sociais com as estratégias de SEM e SEO, e, ações conjuntas como e-mail marketing, sites e hotsites modernos (OKADA, SOUZA, 2011). Os resultados destas práticas podem ser medidos pelas organizações através do desempenho das ações de marketing digital, das interações no ambiente virtual e através de indicadores métricos, como: satisfação dos clientes, conquista de novas clientes, crescimento das vendas, etc. (SARQUIS et al, 2019).

As questões do marketing estratégico envolvem, portanto, a diferenciação, posicionamento, segmentação, marca, inovação, ciclo de vida, entre outras (VARADARAJAN, 2012). Assim, as empresas após analisarem as oportunidades e ameaças no mercado, como também, avaliarem seus pontos fortes e fracos, terão em mãos boas informações para desenvolver estratégias que a beneficie (SRINVASAN et al, 2015). Neste ponto, cabe ressaltar que os 4P's e a análise SWOT apresentam-se como boas ferramentas tradutoras e norteadoras dos objetivos de marketing, sendo de grande auxílio às empresas.

Em relação a um dos componentes dos 4P's, cabe destacar que em muitos casos a "promoção" é utilizada como sinônimo de marketing no Brasil, tanto por pessoas quanto por algumas empresas. Isso aconteceu por três principais motivos: (i) à maioria dos produtos consumidos no país são fabricados em multinacionais, logo a concepção e o desenvolvimento vêm de países externos, sendo realizadas esporadicamente algumas modificações e adaptações locais; (ii) devido aos altos impostos, a legislação tributária em constante mudança e, em um passado não muito distante, terem altas taxas de inflação, o preço sempre foi uma variável difícil de ser administrada; e (iii) devido a distribuição ser dominada por atacadistas e varejistas, este componente passou para a área de produção (CAMPOMAR, IKEDA, 2006). Assim, restou apenas a promoção para que os administradores pudessem de fato gerenciar, ganhando mais importância no processo de marketing (CAMPOMAR, IKEDA, 2006).

Hooley, Piercy e Nicolaud (2011) defendem que a gestão estratégica de marketing precisa se tornar cada vez mais voltada para o mercado, à medida que tal ação leve-a lidar com esse ambiente em constante mudança. Assim, com a instauração de uma nova fase, denominada como "Era da Busca", Okada e Souza (2011) afirmam que o consumidor quer uma comunicação dirigida e flexível, a ponto de permitir que ele participe do projeto do produto. Neste sentido, "as estratégias de marketing podem transformar-se em um processo de aprendizado contínuo e de interação entre os clientes e o mercado" (OKADA, SOUZA, p. 51 2011). Com mais informações acerca do cliente e do mercado, a empresa pode diagnosticar oportunidades, que propiciarão que ela obtenha crescimento e alcance seus objetivos (SARQUIS, 2019).

Deste modo, ressalta-se que é crucial compreender como as organizações empregam seus recursos em diferentes tipos de estratégias de marketing para atingir seus objetivos e, consequentemente, obter vantagem competitiva (SRINVASAN et al, 2015). Contudo, segundo a pesquisa de Coelho et al (2015) os sócios-proprietários das MPMEs agem de forma amadora em relação ao marketing, utilizando o seu feeling do negócio para encarar o ambiente mercadológico. 
Assim, pode-se afirmar que em grande parte dos MPMEs o marketing é feito de forma intuitiva, não existindo muito estudo para implantar determinada atividade (COELHO et al, 2015). Ademais, os autores perceberam que a estratégia adotada por muitos sóciosproprietários de MPES está em recorrer à aprendizagem organizacional concebido através das suas interações com sua rede de contatos, bem como, as suas experiências anteriores, para tomar decisões, desenvolver novos conceitos sobre o negócio e tornar suas práticas de marketing mais fortalecidas.

Outro fator que impacta as estratégias e práticas de marketing está relacionado à cultura organizacional. Segundo Finoti et al (2018) quando a cultura organizacional tem um direcionamento à inovação, ela favorece que todos os colaboradores desenvolvam um capital social que facilita o comportamento inovativo, como acontece em PMEs de tecnologia. Assim, o papel do marketing interno está no direcionamento dos colaboradores para a visão que a organização almeja, fortalecendo sua missão corporativa (FERREIRA FILHO, PEREIRA, PASSOS, 2013).

Por último, algumas empresas criam condições para intensificar a aprendizagem no ambiente organizacional, destacando o importante papel da cultura (OLIVEIRA NETO, SOUZA-SILVA, 2017). Conforme os autores, a cultura da aprendizagem organizacional está centrada na aprendizagem contínua, a qual se sustenta por meio de dois valores: (i) a responsabilidade da aprendizagem, que se refere à capacidade aprender com as próprias experiências profissionais, refletindo a partir dos erros e acertos; e (ii) a informação válida que visa orientar os colaboradores a não distorcer aquilo que foi feito, a fim de obter relatos fidedigno desses desacertos, e assim, favorecer que a empresa desenvolva através de um processo de revisão (OLIVEIRA NETO, SOUZA-SILVA, 2017).

\subsubsection{Estratégias deliberadas versus emergentes}

Por volta de 1960, quando as estratégias entraram em cena no ambiente de negócios, sendo reconhecidas como um importante item para a competitividade das organizações, estavam atreladas a ela o ideário de planejamentos longos, o controle racional do ambiente, bem como, a importância de profissionais capacitados com aparatos técnicos e analíticos (MINTZBERG, 1994). Diante deste cenário, caracterizado por alta carga de rigidez e análise estática do ambiente, as estratégias foram concebidas como fórmulas padronizadas (BORGES JR., LUCE, 2000).

Cerca de vinte anos após a entrada das discussões sobre estratégia na organização, Mintzberg e Waters (1985) desenvolvem os termos estratégias deliberadas e emergentes, acompanhando o aumento da volatilidade do mercado, ocasionada, em grande parte, pela globalização, o avanço das tecnologias de informação e comunicação e pelo amadurecimento do capitalismo em outras nações ao redor do mundo. Esses dois termos demonstram como as estratégias podem surgir no dia-a-dia das organizações.

Quando a estratégia, ora planejada anteriormente, é executada, denomina-se deliberada (MINTZBERG, WATERS, 1985). Nela, está envolvida a ideia de um plano de ação para responder aos acontecimentos do ambiente de forma a maximizar os resultados, sendo assim, uma continuidade dos planejamentos que guardam o formalismo e a rigidez do modelo de administração centralizado, onde somente a cúpula tem capacidade de determinar as ações que as empresas poderiam executar (BORGES JR., LUCE, 2000). 
A estratégia deliberada pode garantir a tranquilidade dos administradores e acionistas em relação às tomadas de decisão de longo e curto prazo da empresa, porém, em um cenário de constantes mudanças, as implicações da utilização deste tipo de estratégia foram rapidamente percebidas pela organização, como a dificuldade de cumprir o planejamento estratégico e a reorientação da empresa para a sua sobrevivência em outro quadro (BORGES JR., LUCE, 2000). Surge então, a estratégia emergente, que reflete a capacidade da organização em se adaptar ao ambiente, formando e executando novas estratégias, sem que exista um planejamento anterior.

A estratégia emergente coloca o ambiente como um fator de extrema importância, uma vez que o mesmo é considerado responsável pelas mudanças de rotas da organização, bem como, de sua evolução dentro do mercado (BORGES JR., LUCE, 2000). Este tipo de estratégia permite também, uma melhor compreensão da dinâmica social que caracteriza o cotidiano da organização (PEREIRA et al, 2014).

\section{$3 \quad$ Procedimentos metodológicos}

O presente estudo se caracteriza por ser uma pesquisa qualitativa, visto que se mostra como uma proposta mais adequada para responder ao objetivo proposto. Este tipo de pesquisa enfatiza a descrição detalhada dos fenômenos, dando voz aos significados, aos depoimentos e aos contextos (VIEIRA, 2006). Ademais, utilizou-se o método de estudo de caso sob as concepções de Stake (2000).

O caso é uma unidade específica que predominam questões sobre relações complexas, portanto, é importante otimizar a sua compreensão (STAKE, 2000). Neste sentido, o presente estudo traduz variadas e complexas relações referentes ao entendimento e desenvolvimento do marketing estratégico, e das práticas de marketing em uma MPME.

Stake (2000) divide os estudos de caso em três tipos: intrínseco, instrumental e coletivo. Assim, seguindo as particularidades do presente estudo que serão exemplificadas a posteriori, pode-se afirmar que este se encaixa como um estudo de caso instrumental, uma vez que o interesse na discussão e na análise do caso pode facilitar a compreensão de algo mais amplo, ou ainda, fornecer um insight sobre determinada temática. No presente caso estudado corresponde às práticas de marketing em MPMEs, o funcionamento e desenvolvimento do marketing estratégico por estas organizações.

Cabe ressaltar que este estudo de caso como qualquer outro não pode ser generalizado. No entanto, como afirma Stake (2000), mais do que a generalização para além do caso, faz-se importante o que é particular em cada caso. Logo, esta investigação preocupou-se em desenvolver e aplicar um protocolo de estudo de caso (FREITAS, JABBOUR, 2011), a fim de oferecer uma visão holística do fenômeno estudado (ALVES-MAZZOTI, 2006).

\subsection{Protocolo do Estudo de caso}

Com objetivo de assegurar a confiabilidade da presente pesquisa, foi elaborado um protocolo inspirado nos estudos de Freitas e Jabbour (2011). Para melhor compreensão das etapas que fazem parte do protocolo apresenta-se o Quadro 1 abaixo.

\section{Quadro 1 - Protocolo}

\begin{tabular}{|c|c|}
\hline Questões Centrais & Detalhes programados e executados na pesquisa \\
\hline Questão Principal da Pesquisa & Como uma MPME que passou por um programa de incubação de empresa \\
\hline
\end{tabular}




\begin{tabular}{|l|l|}
\hline & $\begin{array}{l}\text { utiliza o marketing estratégico para se estabelecer e crescer em seu } \\
\text { mercado de atuação? }\end{array}$ \\
\hline Temas de Sustentação Teórica & $\begin{array}{l}\text { Marketing Estratégico; Estratégias deliberadas; Estratégias Emergentes; } \\
\text { práticas de marketing e cultura organizacional. }\end{array}$ \\
\hline Definição do Objeto de Estudo & Compreensão da utilidade do marketing estratégico em MPMEs. \\
\hline Definição da Unidade de Análise & Empresa Inova GS. \\
\hline $\begin{array}{l}\text { Potenciais Entrevistados e e } \\
\text { Múltiplas Fontes de Evidências }\end{array}$ & $\begin{array}{l}\text { Sócio-proprietário da Inova GS, Paulo Martins. Site da empresa. Redes } \\
\text { sociais (Linkedin e Facebook). }\end{array}$ \\
\hline Período de realização & Agosto de 2019 a Outubro de 2019. \\
\hline Local da coleta de Evidências & Internet para coleta de informações públicas e entrevista por Skype. \\
\hline Síntese do roteiro de entrevista & $\begin{array}{l}\text { As questões do roteiro de entrevistas contemplavam os temas: histórico da } \\
\text { empresa, marketing estratégico, práticas de marketing, missão, visão e } \\
\text { cultura organizacional, e planejamento estratégico de marketing. }\end{array}$ \\
\hline
\end{tabular}

Fonte: adaptado pelas autoras de Freitas e Jabbour (2011).

Tal protocolo pode servir para futuramente replicar o estudo, ou até mesmo aplicá-lo em outro caso que possua características semelhantes com esta pesquisa.

\subsection{Processo da coleta de dados e Técnica de análise dos dados}

Para melhor condução desta pesquisa, efetuou-se um planejamento para a coleta dos dados, segundo o que foi proposto por Freitas e Jabbour (2011). Consistindo em seis etapas, os dados obtidos podem caracterizar e explicar da melhor maneira o fenômeno pesquisado. $\mathrm{O}$ Quadro 2 exemplifica todo o processo realizado para a obtenção destes dados.

\section{Quadro 2 - Processo da Coleta de Dados}

\begin{tabular}{|c|c|}
\hline Etapas & Detalhes programados e executados na pesquisa \\
\hline $\begin{array}{l}\text { Contato formal com } \\
\text { a organização }\end{array}$ & $\begin{array}{l}\text { primeiro contato com a organização foi realizado no dia } 29 \text { de setembro de } 2019 \text {, } \\
\text { través do envio de um e-mail dentro do próprio site da Inova GS. Neste e-mail foi } \\
\text { xplicado as razões e as justificativas do presente estudo, bem como, a importância da } \\
\text { rganização para o sucesso do mesmo. }\end{array}$ \\
\hline $\begin{array}{l}\text { Explanação dos } \\
\text { objetivos do estudo } \\
\text { para a organização }\end{array}$ & $\begin{array}{l}\text { Através de contato telefônico, efetuou-se outra comunicação diretamente com um dos } \\
\text { sócios-proprietários da empresa. Nesta conversa, explicou-se de forma mais detalhada o } \\
\text { objetivo geral e os objetivos específicos da pesquisa, como também, o papel da } \\
\text { organização e do próprio sócio no desenvolvimento da mesma, que consistiria em dividir } \\
\text { as experiências, as ações e as práticas de marketing estratégico que envolvia o ambiente } \\
\text { organizacional da Inova GS. }\end{array}$ \\
\hline 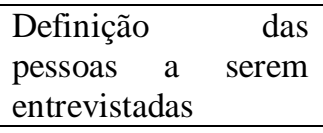 & $\begin{array}{l}\text { nesmo, por ter mais afinidade } \\
\text { ia a cargo de participar da }\end{array}$ \\
\hline $\begin{array}{l}\text { Realização } \\
\text { entrevista }\end{array}$ & 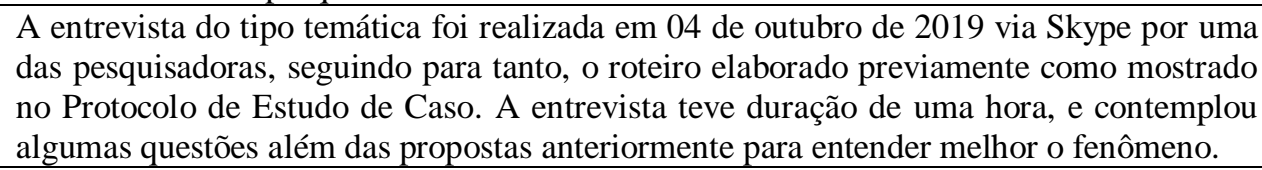 \\
\hline $\begin{array}{l}\text { Coleta de dados nos } \\
\text { sites e redes sociais } \\
\text { da organização }\end{array}$ & dos produtos, história, anúncio de vaga e publicidade da empresa. \\
\hline
\end{tabular}
Fonte: adaptado pelas autoras de Freitas e Jabbour (2011).

Com todos os dados coletados, a próxima fase da pesquisa consistiu na análise dos mesmos. Para tanto, utilizou-se a análise de conteúdo de acordo as recomendações de Bardin 
(1979). Esta técnica foi utilizada não somente para a análise da entrevista realizada por Skype, mas também, serviu para analisar as informações públicas coletadas no site e redes sociais da empresa Inova GS.

Deste modo, na primeira fase denominada de pré-análise, transcreveu-se a entrevista e, em seguida, foi realizada a leitura flutuante da mesma. Realizou-se também nesta fase a leitura flutuante das demais informações públicas coletadas. Esses passos se mostraram fundamentais para obter um maior contato com os dados, auxiliando na identificação das respostas de cada objetivo. Assim, optou-se por trabalhar com categorias mistas, ou seja, emergidas da teoria e dos dados coletados, as quais foram: práticas de marketing; resultados das práticas de marketing; oportunidades de mercado; planejamento estratégico de marketing; estratégias emergentes; estratégias deliberadas; aprendizagem organizacional; felling do empreendedor; cultura organizacional; e papel da incubadora.

$\mathrm{Na}$ segunda fase, denominada de exploração do material, codificou-se a entrevista e as informações coletadas, por meio de recortes e classificação de trechos considerados relevantes para as categorias criadas na fase anterior. Na última fase, denominada de tratamento dos resultados obtidos e interpretação, utilizou-se a análise temática para responder os objetivos propostos. Para melhor interpretação e validade dos resultados, buscou-se relacionar constantemente os temas empíricos encontrados na pesquisa com a fundamentação teórica.

\subsection{Objeto do Estudo e Unidade de Análise}

Conforme apontado nas discussões do referencial teórico sobre a dimensão do marketing estratégico para as organizações, e ressaltando ainda a importância de compreender como as organizações empregam seus recursos em diferentes tipos de estratégias de marketing para atingir seus objetivos, obtendo consequentemente, vantagem competitiva, o presente artigo tem como objeto de estudo a compreensão da utilidade do marketing estratégico pelas MPMEs.

Ademais, este artigo tem como unidade de análise a empresa Inova GS. A escolha desta unidade de análise se deu pelo fato que dentre todas as empresas avaliadas em termos de premiações e destaques em ambientes de inovação, a Inova GS se sobressaiu, obtendo a melhor nota dentre as empresas que se graduaram no Programa Municipal de Inovação de Santa Rita do Sapucaí - MG (PROINTEC). Outro destaque da Inova GS se deu na sua participação no InovAtiva Brasil, um programa de aceleração de Startup criado pelo Ministério da Indústria, Comércio Exterior e Serviços (MDIC).

Não somente a história da Inova GS está cercada de destaque, mas também, as dos empreendedores, os quais conceberam a empresa ainda na Faculdade. Ambos, em 2012, participaram do Desafio Universitário Empreendedor realizado pelo Sebrae, onde, se tornaram os campeões mineiros naquele ano e ocuparam o terceiro lugar do Brasil. A partir daí, a vontade de empreender aumentou, fazendo com que eles conquistassem outras premiações, como o primeiro lugar na FAITEC - Feira Tecnológica da FAI e no Prêmio Municipal de Inovação de Santa Rita do Sapucaí, através do desenvolvimento de um jogo de gestão de negócios no ano de 2014.

O sucesso no desenvolvimento do jogo deu suporte para que eles buscassem apoio em uma incubadora de empresa. A trajetória da Inova Gs iniciou assim, na incubadora $\mathrm{X}^{1}$ e,

${ }^{1}$ Omitiu-se o nome da incubadora por questões éticas. 
posteriormente, migraram para a IME - Incubadora Municipal de Empresas de Santa Rita do Sapucaí, onde a empresa se graduou. Atualmente a empresa conta com 15 colaboradores, e tem no seu portfólio de produto/serviço um dos principais portais de estágios da América Latina que atinge cerca de 15 milhões de visualizações mensais, tendo como clientes cerca de 70 grandes organizações.

Apresentado esse histórico, bem como, tendo em vista que a Inova GS ainda é uma PME, e como tal está sujeita aos diversos desafios que compreendem as organizações deste tipo, torna-se relevante entender a utilidade do marketing estratégico dentro do seu ambiente organizacional. Além disso, mostra-se como um caso interessante de ser entendido, observado e estudado no âmbito acadêmico devido às suas particularidades.

\section{Discussão dos resultados: Caso Inova GS}

A fim de atender aos objetivos propostos e facilitar compreensão dos dados, a apresentação dos resultados abrange os seguintes temas: práticas de marketing estratégicas adotadas pela empresa; relação entre as estratégias deliberadas e emergentes no contexto da organização; Implicação da aprendizagem organizacional e o felling do empreendedor na cultural organizacional; e Tópico Especial: papel da incubadora de empresa.

\subsection{Práticas de Marketing Estratégicas adotadas pela empresa}

Em relação às práticas de marketing utilizadas pela Inova GS para se estabelecer e crescer em seu mercado de atuação, identificou-se que as mesmas se concentravam na divulgação dos produtos/serviços ofertados pela empresa, procurando engajamento com seus clientes. Tais práticas, de maneira geral, estão embasadas em ferramentas tecnológicas e têm sido dispostas em mídias digitais que foram desenvolvidas e adotadas recentemente pelo mercado. Isso acaba propiciando que a empresa demonstre aos seus clientes e, até mesmo concorrentes, seu potencial inovador.

Quadro 3 - Práticas de Marketing

Trechos da entrevista com o sócio proprietário

A estratégia que a gente tem hoje aborda muitos pontos de marketing (...), por exemplo, nós utilizamos e-mail marketing, What'sApp Business, Linkedin, Facebook e Instagram (ENTREVISTA, p. 5).

Estamos utilizando um CRM inteligente, então os clientes, os parceiros e os usuários que estão cadastrados na nossa plataforma (Estágio Online) vão ganhando pontos à medida que consomem nossos conteúdos e acessam as informações que eles disponibilizam (ENTREVISTA, p. 5).

\section{Trecho de anúncio de vaga}

Estágio em Customer Success: engajar nossos seguidores, clientes e parceiros através de conteúdos relevantes e de qualidade.

Fonte: Elaborado pelas autoras (2019).

Conforme os relatos acima, foi possível retomar a discussão levantada pelos autores Campomar e Ikeda (2006) em relação ao destaque de um dos componentes dos 4P's, em específico, a "Promoção". De acordo com os autores, no contexto brasileiro devido a alguns fatores críticos do ambiente mercadológico, sobrou apenas a "Promoção" para que os administradores pudessem de fato gerenciar, consequentemente, esta ganhou mais importância no processo e em muitos casos é utilizada também como sinônimo de marketing, tanto por pessoas quanto por algumas empresas. 
Para a empresa Inova GS, os resultados das práticas estratégicas de marketing realizadas pela sua equipe podem gerar resultados variados, perpassando desde um valor baseado no prestígio e reconhecimento da marca no mercado (através de curtidas, comentários, engajamento com os usuários), e até mesmo gerar resultados financeiros, por meio de um maior número de vendas, fidelizações dos clientes e contratos fechados.

\section{Quadro 4 - Resultado das práticas de Marketing}

\section{Trecho da entrevista com o sócio proprietário}

Quando a gente está falando de resultados estou falando de número de cadastros, lides que a gente coleta, comentários, visualizações, alcance de público, engajamento de público, e retorno inclusive financeiro, então são vários tipos de retornos que a gente espera (ENTREVISTA, p. 6).

Membros: 12.721 pessoas

Curtidas: 819.595

Facebook Estágio Online

Seguidores: 1.206 pessoas

\section{Facebook Inova GS}

Fonte: Elaborado pelas autoras (2019).

Neste ponto, foi possível corroborar com Sarquis (2019) o qual afirma que os resultados das práticas de marketing podem ser medidas através de vários índices baseados nas ações de marketing digital, como as interações no ambiente virtual, e ainda, através de indicadores métricos, como: satisfação dos clientes, conquista de novas clientes, crescimento das vendas, entre outros.

Ainda voltada para o seu crescimento no mercado, a empresa Inova GS demonstra preocupação em atender as necessidades de seus clientes, enfatizando a importância de se conseguir visualizar oportunidades no mercado para o lançamento de produtos/serviços, bem como, para o sucesso das estratégias de negócio.

Acho que o mais interessante é você ir desenvolvendo (os produtos/serviços) à medida que seus clientes vão pedindo pra você, porque cliente hoje é quem paga as contas, então é ele quem demanda isso, e a gente tem que entender o que o cliente está querendo, desenvolver isso e entregar para ele (ENTREVISTA, p. 11).

Neste sentido, a gestão estratégica da Inova GS tende a valorizar a questão do marketing orientado ao cliente e às oportunidades de mercado, visto que a própria história da empresa retrata um case de sucesso advindo pela utilização de tal estratégia, como foi contado por um dos sócios a respeito da criação de um de seus produtos, o EstágioOnline.com.

No começo, como eu te disse, a ideia era ter um jogo de negócios, um game, que seria utilizado por universitários no Brasil inteiro, em substituição do desafio SEBRAE, no entanto, não foi o que aconteceu. O segundo pensamento foi: vamos utilizar o que a gente fez (jogo de negócios) para vender para outras faculdades, então a gente vai preparar uma ferramenta agora que não é tão cara de joguinho, e sim (...) uma ferramenta de ensino, de gestão mesmo, de negócios, e a gente vai vender para o mercado de educação, para universidades. Começamos a fazer isso, mas estava muito fraco de acontecer, não estava vendendo, as instituições de ensino estavam segurando dinheiro, porque era uma época em que o governo não estava repassando verba e aí elas estavam comprando aquilo que era extremamente necessário, aquilo que elas já conheciam, então meio que não existia compra para 
empresas novas, produtos novos, sabe?! (...) o mercado de educação estava muito fraco, foi onde surgiu o Estágio Online. Foi uma época que aumentou muito a divulgação de que mais pessoas estavam ficando desempregadas, aí "passava" na televisão direto, dez milhões de desempregados no Brasil, aí na outra semana estava lá, onze milhões desempregados no Brasil, aí na outra semana, doze milhões, aí a gente resolveu criar alguma coisa que levasse ao público oportunidades de emprego, que fosse de conhecimento das pessoas. Como a gente andava com uma ferramenta direcionada para o público estudante, instituição de ensino, e tudo mais, a gente quis criar uma coisa que fosse voltada para o estágio, e aí a gente criou o EstágioOnline.com que deu muito certo (...) e a gente começou a ter retorno disso, financeiro já. E cresceu muito rápido, e as empresas começaram a buscar a gente para divulgar vagas, e o número de estudantes cadastrados foi aumentando muito. A gente começou nisso, começou mas não parou, o game, o jogo empresarial ali foi maturando né, aí começou a ter uma demanda para o game que era de treinamentos coorporativos, que inclusive começou a dar mais retorno do que as próprias universidades (ENTREVISTA, p. 9).

As falas do sócio-proprietário reafirmam a importância da análise das oportunidades e ameaças no mercado, como boas informações para desenvolver estratégias de negócios (SRINVASAN et al, 2015), visto que mais informações acerca do cliente e mercado propicia à empresa que ela obtenha crescimento e alcance de seus objetivos (SARQUIS, 2019). Reforça-se assim, as colocações de Hooley, Piercy e Nicolaud (2011) em relação à necessidade da gestão estratégia de marketing estar voltada para o mercado, caracterizado pelas constantes mudanças.

Além do mais, a entrevista corroborou a existência da "Era da Busca" colocada pelas autoras Okada e Souza (2011), visto que o sócio-proprietário enfatiza a importância de desenvolver produtos/serviços à medida que seus clientes vão pedindo, retomando as falas das autoras: o consumidor quer uma comunicação dirigida e flexível a ponto de permitir que ele participe do projeto do produto.

\subsection{Relação entre as estratégias deliberadas e emergentes no contexto da organização}

Quando questionado sobre a realização do planejamento estratégico de marketing, os sócios-proprietários da empresa foram enfáticos ao afirmar que apesar de realizarem um plano anual e trimestral com metas e objetivos a serem cumpridos, eles o consideram pouco relevante, devido à variabilidade e mutabilidade do ambiente, que é caracterizado pelo crescente lançamento de novas tecnologias, produtos e inovações. Assim, para os sócios o planejamento estratégico de marketing se seguido à risca pela organização, pode fazer com que a empresa perca competitividade e não corresponda de forma adequada aos desafios do macro-ambiente organizacional.

\section{Quadro 5 - Planejamento Estratégico de Marketing}

\section{Trechos da entrevista com o sócio proprietário}

Então é um planejamento que a gente cumpriu com o edital, ele nos abriu os olhos para o que tinha que fazer, mas não necessariamente é o que a gente executou ao longo do tempo, a gente tem muito uma visão de adaptação do que aconteceu (ENTREVISTA, p. 3).

Todo ano a gente faz a matriz SWOT, a gente coloca quais são os pontos fortes, os pontos fracos, as ameaças, as fraquezas que a Inova GS possui. E a gente vai trabalhando nelas ao longo do ano, então a gente tem esse planejamento todo o começo de ano, e igual eu falei novamente, ele vai sofrendo adaptações e mudanças ao longo do ano (ENTREVISTA, p. 6). 
No nosso caso muda muito rápido, surge muita ferramenta, há uns quatro meses atrás a gente não usava um CRM de inteligência, agora a gente usa um CRM com inteligência, mas o planejamento que a gente fez lá em 2014 a gente nem sabia que isso existia, então não dá (ENTREVISTA, p. 10).

Fonte: Elaborado pelas autoras (2019).

Tais colocações ilustram a afirmação de Mckenna (2000), que remete as mudanças advindas da tecnologia não modificam somente o mercado, mas também contribui para modificar as atividades de marketing, como pode ser observado nas grandes empresas, onde a maioria das modificações tem sido de reação e não de previsão.

Em seguida, em relação às estratégias denominadas pela literatura como deliberadas, onde estão envolvidas a ideia de um plano de ação para responder aos acontecimentos do ambiente de forma a maximizar os resultados, os sócios mencionam apenas que mantém algum formalismo referente as formas de divulgação da empresa.

A gente tem aqui uma estratégia de quantidade de publicações que são feitas, em que momento, em que horário, de que forma elas são feitas, que linguagem essas publicações utilizam para atingir mais pessoas de determinada região (ENTREVISTA, p. 6).

Como pode ser observado, a forma de enxergar as estratégias de marketing pelos sócios-proprietários refletem os posicionamentos de Borges Jr. e Luce (2000), os quais afirmam que as estratégias deliberadas dão tranquilidade aos administradores em relação às tomadas de decisões, contudo, em um cenário de mudanças, as organizações precisarão modificá-las, para sua sobrevivência em outro quadro. Como afirma o sócio-proprietário "até dá pra ter um planejamento em longo prazo, mas você tem que ter a noção que você vai ter que mudar todo o dia, se você quiser se manter no mercado" (ENTREVISTA, p. 10).

Assim, é possível perceber que os sócios-proprietários da empresa se mostram muito mais aderentes às estratégias emergentes, ou seja, aquelas que surgem como resposta as oportunidades/desafios do mercado, considerando-as mais válidas para gerar competitividade à empresa.

Quadro 6 - Estratégias Emergentes

\section{Trechos da entrevista com o sócio proprietário}

Atualmente, essa plataforma (Estágio Online) é um dos principais portais de estágios da América Latina, a gente atingi mais ou menos entre quinze a vinte milhões de visualizações mensais nas nossas publicações, (...), então como a gente conseguiu isso né, nosso planejamento estratégico adaptativo digamos assim (ENTREVISTA, p. 34).

Hoje, por exemplo, a principal rede pra gente não é o Facebook, mas sim o LikedIn que cresce mais, traz mais resultado, mas não era, então a gente vai direcionando a estratégia de acordo com o que vai mudando no mercado (ENTREVISTA, p. 4).

Uma coisa que era um ponto forte (...), pode não ser mais um diferencial nosso, porque outra empresa agora oferece a mesma coisa, então já não é um ponto que nos diferencia ou qualquer outra coisa do mercado em relação aos clientes, por exemplo. Então, à medida que as tecnologias vão surgindo nós vamos dando jeito de testá-las também com o nosso público (ENTREVISTA, p. 5).

A gente vai "pivotando" as ideias inicias frequentemente. Cada trimestre a gente analisa o resultado que deu e muda a direção, muda o foco, atualiza o que a gente está fazendo (ENTREVISTA, p. 9).

Fonte: Elaborado pelas autoras (2019). 
As falas do sócio-proprietário demonstram a importância de a estratégia emergente considerar o ambiente como um fator de extrema importância, uma vez que o mesmo é considerado responsável pelas mudanças de rotas da organização, bem como, de sua evolução dentro do mercado como é colocado por Borges Jr. e Luce (2000).

Ademais, observa-se que as estratégias adotadas pela Inova GS conforme apresentadas pelas falas do sócio, ilustra a afirmação de Pereira et al (2014), os quais defendem que as estratégias emergentes permitem uma melhor compreensão da dinâmica social, que caracterizam o cotidiano da organização.

\subsection{Implicação da aprendizagem organizacional $e$ o felling do empreendedor no marketing estratégico adotado pela empresa}

Durante a entrevista, o sócio-proprietário retratou vários momentos em que ele e sua equipe se valeram da própria aprendizagem organizacional, ou seja, dos erros e acertos, para identificar a melhor estratégia a ser tomada. Deste modo, muitas decisões da equipe de marketing eram baseadas em testes, no histórico organizacional e através de estudos desenvolvidos pelos próprios colaboradores.

\section{Quadro 7 - Aprendizagem Organizacional}

\section{Trechos da entrevista com o sócio proprietário}

A gente estudou muito como as redes sociais funcionavam. Vem Facebook, Instagram, LikedIn e muda o algoritmo (...) e o que nós fazíamos era entender o que havia mudado, e depois a gente se adaptava pra isso (ENTREVISTA, p. 4).

A gente olha para base e estuda como a gente vai divulgar isso, faz o filtro, e aí a gente decide se vai fazer por email marketing, sms, WhatsApp Bussiness, e segmentamos a forma que vamos fazer (ENTREVISTA, p. 5).

(...) se desse certo a gente anota, gera informações, a gente sempre usou de ferramentas como Google Analytics, Similar Web, pra analisar informações do que realmente está acontecendo (ENTREVISTA, p. 7).

A gente está sempre olhando aqueles concorrentes que estão fazendo sucesso, o que está dando certo para eles, o que está levando eles a determinado patamar. Que a gente pode não fazer igual, mas o que a gente pode usar como inspiração para poder melhorar, ou fazer no mesmo ponto, ou melhor do que eles (ENTREVISTA, p. 11).

Fonte: Elaborado pelas autoras (2019).

A perspectiva que a Inova GS adere em relação à importância das tentativas e erros na construção da aprendizagem organizacional, retoma as conclusões do trabalho de Coelho et al (2015), os quais perceberam que a estratégia adotada por muitos sócios-proprietários de MPES está em recorrer à aprendizagem organizacional, a qual, muita das vezes, é concebida através das interações da empresa com sua rede de contatos e de suas experiências anteriores.

Esta aprendizagem organizacional é utilizada para a tomada de decisões, para o desenvolvimento de novos conceitos sobre o negócio e, inclusive, para tornar suas práticas de marketing mais fortalecidas (COELHO et al, 2015). Como pode ser corroborado na fala do sócio-proprietário: "então era teste, faz uma coisa, não funciona, muda, faz de novo, outra coisa dá mais certo que essa. Aí depois isso vai gerando um histórico pra gente. A gente vai olhando para o que deu certo e vai replicando isso para os próximos" (ENTREVISTA, p. 4).

Ademais, na entrevista foi percebido também que os sócios-proprietários da Inova GS tendem a valorizar o seu "felling empreendedor" sobre seu negócio, afirmando que muitas das tomadas de decisões foram feitas baseadas no que ambos consideravam importante para o crescimento, manutenção e sucesso do negócio. 


\section{Quadro 9 - Felling do Empreendedor}

Trechos da entrevista com o sócio proprietário

Tanto eu como meu sócio nós não temos formação nenhuma em marketing, é em TI e desenvolvimento mesmo, e parte de tecnologia, mas a gente fazia uma coisa diante do que a gente acreditava que poderia dar certo (ENTREVISTA, p. 7).

A missão e visão da empresa foi muito do que eu e o outro sócio acredita (ENTREVISTA, p. 8).

Nós desenvolvemos um produto durante três anos, geralmente daquilo que a gente acredita que daria certo, então era um pensamento meu e do meu sócio, do que a gente achava que poderia dar certo no mercado e a gente demorou três anos pra fazer, e quando a gente chegou no mercado para vender a gente descobriu e não era bem isso (ENTREVISTA, p. 11).

$$
\text { Fonte: Elaborado pelas autoras (2019). }
$$

De certa forma, tais atitudes baseadas no "felling do empreender" demonstram certo amadorismo característico dos MPMES. Conforme Coelho et al (2015) os sóciosproprietários das MPMEs agem de forma amadora em relação ao marketing, utilizando o seu feeling do negócio para encarar o ambiente mercadológico. Assim, observa-se que em grande parte dos MPMEs, algumas estratégias são realizadas de forma intuitiva, como é o caso da Inova GS. Logo, tal "felling" pode propiciar que os empreendedores façam escolhas desacertadas e errôneas, fazendo consequentemente, que a empresa não responda de forma adequada ao mercado, como é observado na fala do sócio-proprietário.

A cultura organizacional, neste sentido, expressa os fatores pontuados acima. Assim, no ambiente organizacional está à maior presença de jovens com pouca experiência no mercado de trabalho, mas com uma mente aberta para "aprender-fazendo"; trazer coisas novas; e utilizar sua criatividade. Por considerarem importante a aprendizagem organizacional os sócios-proprietários tendem a valorizar o mesmo tipo de comportamento em seus colaboradores.

\section{Quadro 10 - Cultura Organizacional}

\section{Trechos da entrevista com o sócio proprietário}

Toda empresa tem uma cultura, e a gente está formando a nossa, como eu te disse, a gente tem o time muito novo, muito jovem, e a gente quer ter essa cultura jovem aqui né?! De trazer coisas novas, pensamentos novos, fazer o que a gente pensa, o que a gente acha que é interessante utilizar, que seja literalmente vivenciado pelas pessoas, não só uma coisa bonitinha pra ser colocado no papel, porque literalmente assim não serve pra nada (ENTREVISTA, p. 8).

A gente tem um perfil de time muito jovem, são pessoas que estão ou estudando, ou acabaram de se formar, então muitos deles não tem experiência com mercado ainda, e aqueles que têm a experiência tem que mudar o raciocínio, mudar a forma de pensar (ENTREVISTA, p. 6).

Das vezes que a gente testou deixar as pessoas que tinham o conhecimento, que tinha a experiência anterior fazer uma tarefa, foram as vezes que a gente não obteve resultado (ENTREVISTA, p. 7).

\section{Anúncio de emprego}

Se você tem mentalidade jovem, é uma pessoa que provoca mudanças positivas no meio em que vive, que sabe que o resultado da empresa reflete o esforço coletivo e o resultado individual aplicado, que não sabe deixar as coisas para depois e tem, acima de tudo ATITUDE para fazer acontecer, venha fazer parte do time \#Inovers e nos ajude a transformar a vida de outras pessoa.

$$
\text { Fonte: Elaborado pelas autoras (2019). }
$$

As ações da Inova GS retomam a afirmação de Oliveria Neto e Souza-Silva (2017) que empresas que desejam criar condições para intensificar a aprendizagem no ambiente organizacional, precisa destacar o importante papel da cultura. Neste sentido, a cultura da 
aprendizagem organizacional da empresa induz que os colaboradores se capacitem para exercer suas atividades através das suas próprias experiências profissionais, dos seus erros e acertos, retomando deste modo o trabalho de Oliveira Neto e Souza-Silva (2017). Por outro lado, o sócio-proprietário mostra aversão às experiências anteriores dos colaboradores que foram obtidas fora da Inova GS, seja em outra organização ou na academia.

\subsection{Tópico Especial: papel da incubadora de empresa}

Durante a entrevista, o sócio-proprietário da empresa mencionou alguns benefícios que a Inova GS obteve em estar instalada em uma incubadora de empresas, especificamente na IME - Incubadora Municipal de Empresas de Santa Rita do Sapucaí. No entanto, ele também mencionou alguns pontos negativos deste ambiente de inovação, como a falta de um programa de incubação referente à primeira incubadora, da qual a empresa fazia parte.

\section{Quadro 11 - Papel da Incubadora}

\section{Trechos da entrevista com o sócio proprietário}

A incubadora tinha parceria com outros consultores empresariais, que foram fundamentais para gente ter mais propriedade do negócio, momentos de negociar com os investidores, de ter mais atenção nos contratos, na documentação, no processo que a gente estava seguindo de gestão de negócios foi de fundamental importância para gente (ENTREVISTA, p. 3). [IME Incubadora Municipal]

A gente contou muito com o apoio da Incubadora Municipal devido ao programa de incubação e por deter uma maior visibilidade (ENTREVISTA, p. 3).

$\mathrm{Na}$ incubadora da $\mathrm{X}$ contávamos mais com o espaço cedido e alguns mini-cursos, não havia um programa de incubação, então foi muito superficial o auxílio desta incubadora (ENTREVISTA, p. 2).

A gente desenhou sim um planejamento de marketing com apoio da incubadora, com apoio dos consultores, mas não necessariamente aquilo que foi executado (ENTREVISTA, p. 4). [IME Incubadora Municipal]

Normalmente a incubadora pede que a gente faça (o planejamento) olhando cinco anos pra frente, mas é inútil (ENTREVISTA, p. 10). [IME Incubadora Municipal]

Fonte: Elaborado pelas autoras (2019).

Conforme o sócio-proprietário da empresa, a Incubadora Municipal de Santa Rita do Sapucaí através de seu programa de incubação deu importante suporte para o gerenciamento de todo seu empreendimento, o que auxiliou no desenvolvimento e consolidação do seu negócio no mercado (ANPROTEC, 2012). Ele retomou ainda a importância dos consultores empresariais nas tomadas de decisões do negócio. Contudo, devido as crescentes mudanças no cenário de atuação da empresa, o mesmo apresenta descrença em relação ao desenvolvimento dos planejamentos estratégicos.

\section{Considerações Finais}

O presente artigo demonstrou a visão da empresa Inova GS sobre a aplicação das ferramentas do marketing estratégico. Acredita-se que por ser um estudo de caso único, o estudo dessa empresa se torna relevante por estar localizada em um município do sul de Minas Gerais, considerado um polo tecnológico e de inovação. Além disso, a empresa estudada participou de um programa de incubação, onde há auxílios e recursos disponíveis que fortaleceram a empresa dentro de seu mercado de atuação.

Para a empresa estudada, os maiores benefícios de se utilizar o marketing estratégico está em gerar para a marca prestígio e reconhecimento no mercado, fidelizações de clientes, maior número de contratos fechados e, consequentemente, resultados financeiros. Contudo, a 
Inova GS considera que seguir à risca o planejamento estratégico de marketing, acarretaria perda de competitividade, visto que a empresa não conseguiria responder de forma adequada os desafios apresentados pelo mercado.

Como o mercado de atuação da empresa é bastante dinâmico, com mudanças rápidas e repentinas, a empresa valoriza muito mais as estratégias emergentes, pois estas respondem e atendem aos desafios que o mercado apresenta. É através das estratégias emergentes que a empresa entende que consegue se manter competitiva no mercado. Outro ponto a ser destacado, é a valorização da empresa pela aprendizagem organizacional, através de erros e acertos anteriores que possibilitam o entendimento de qual decisão tomar, de forma que esta seja a melhor para atender aos objetivos da organização.

Com relações as contribuições trazidas por este artigo, é possível entender que as contribuições gerenciais giram em torno da compreensão de como o marketing estratégico auxilia uma MPME, do setor de tecnologia, enfatizando principalmente a questão da implicação da mutabilidade do mercado nas estratégias da organização. Sobre as contribuições acadêmicas, ainda que se tratando de um caso único, corrobora com as discussões acerca de como o marketing estratégico pode ser aplicado, por diferentes empresas, e de diferentes formas, dada as suas áreas de atuação.

Por fim, sugere-se como estudos futuros, uma pesquisa que tenha como unidade de análise diversas empresas da área de tecnologia, e que contem com o auxílio de uma incubadora. Assim, seria possível realizar uma comparação entre os aspectos considerados relevantes dentro do marketing estratégico de cada uma delas, além de poder confirmar a preferência dessas empresas por trabalhar com estratégias emergentes.

\section{Referências bibliográficas}

ALVES, C. A. Capacidades de Marketing e Inovação Organizacional: Uma relação para vantagem competitiva. Revista Alcance, v. 23, n. 1, p. 92-110, jan./mar., 2016.

ALVES-MAZZOTTI, A. J. Usos e abusos dos estudos de caso. Cadernos de Pesquisa, v. 36, n. 129, p. 637-651, set./dez., 2006.

ANPROTEC. Estudo, Análise e Proposições sobre as Incubadoras de Empresas no Brasil Relatório Técnico. Brasília: ANPROTEC, 2012. Disponível em: $<$ http://www.anprotec.org.br/ArquivosDin/Estudo_de_Incubadoras_Resumo_web_22-

06_FINAL_pdf_59.pdf>. Acesso em 30 de ago. 2019.

BANCO DO NORDESTE. Informe ETENE - MPE. 2018. Disponível em: <https://www.bnb.gov.br/documents/80223/4079612/INFORME+MPE+01-

161018.pdf/fa7c71a1-5401-0c37-666d-7cc7df1 eeaec>. Acesso em 30 de ago. 2019.

BORGES JR., A. A.; LUCE, F. B. Estratégias emergentes ou deliberadas: um estudo de caso com os vencedores do prêmio "Top de Markeitng" da ADYB. RAE, v. 40, n. 3, 2000.

BROZE, T. S.; FACÓ, R. T.; SILVA, L. C. S.; SOUZA, J. S.; CATEN, C. S. T. C. Fatores que influenciam o desenvolvimento de empresas incubadas: uma pesquisa de perspectiva. Brazilian Journal of Business, Curitiba, v. 1, n. 1, p. 127-141, jan./mar., 2019.

CAMPOMAR, M. C.; IKEDA, A. A. Falácias em Marketing no Brasil. Anais... Rio de Janeiro: ANPAD, 2006.

COELHO, R. L. F.; MIRANDA, J. R.; CAMARGO FILHO, A.; FREITAG, M. S. B.; ALMEIDA, M. I. S. Gestão do marketing em micro e pequenas empresas. Regepe, v. 4, n. 2, p. 219-250, 2015. 
FERREIRA, A. I.; PIRES, M. M.; BUSTAMANTE, T. T.; OLIVEIRA, F. A Economia Global e o mercado interno das pequenas e médias empresas. Revista Científica UNILAGOS, v. 1 , $\mathrm{n}$. 1, p. 1-14, 2018.

FERREIRA FILHO, E. P.; PEREIRA, F. A.; PASSOS, G. S. A influência do endomarketing e da comunicação interna na cultura organizacional. Anais... Resende/RJ: Simpósio de Excelência em Gestão e Tecnologia - SEGeT. 2013.

FINOTI, L. L.; DIDONET, S. R.; TOALDO, A. M. M.; COSTA, J. C. N. A influência da Inovatividade no processo de estratégia de marketing e o impacto sobre o desempenho organizacional: evidências do setor TIC. REMark - Revista Brasileira de Marketing, São Paulo, v. 17, n. 2, p. 166-186, abr./jun., 2018.

FREITAS, W. R. S.; JABBOUR, C. J. C. Utilizando estudos de casos como estratégia de pesquisa qualitativa: boas práticas e sugestões. Estudo \& Debate, Lajeado, v. 18, n. 2, p. 07-22, 2011.

HOOLEY, G.; PIERCY, N. F.; NICOLAUD, B. Estratégia de Marketing e Posicionamento Competitivo. 4 ed. São Paulo: Pearson Prentice Hall, 2011.

MCKENNA, R. As cinco regras do novo Marketing. HSM Management, v. 22, ano 4, set./out., 2000.

MINTZBERG, H. The fall and rise of strategic planning. Harvard Business Review, reprint 94107, p. 107-115, 1994.

MINTZBERG, H.; WATERS, J. A. Of Strategies, Deliberate and Emergent. Strategic Management Journal, v. 6, n. 3, p. 257-272, jul. 1985.

OLIVEIRA NETO, C. C.; SOUZA-SILVA, J. C. Aprendizagem, mentoria e cultura organizacional de aprendizagem: o estudo do caso da performance consultoria e auditoria. REAd, Porto Alegre, v. 23, n. especial, p. 60-92, dez., 2017.

OKADA, S. I.; SOUZA, E. M. S. Estratégias de Marketing Digital na Era da Busca. REMark Revista Brasileira de Marketing, São Paulo, v. 10, n.1, p. 46-72, jan./abr., 2011.

PEREIRA, J. A.; SOUZA, M. C. D.; TATTO, L.; OLIVEIRA, J. S. Estratégia como prática: um estudo em empresas incubadas de base tecnológica. RAIMED, v. 4, n. 2., p.161-176, mai./ago., 2014.

SARQUIS, A. B.; HOECKESFELD, L.; CITTADIN, J.; LENZI, F. C. Práticas Contemporâneas de Marketing na Perspectiva Relacional em Empresas de Serviços de Contabilidade. Revista de Contabilidade, Gestão e Governança, v. 22, n. 1, p. 59-84, jan./abr. 2019.

SILVA, R. B.; VIEIRA, L. B. A importância do Planejamento Estratégico de Marketing na formulação do Plano de Negócios. Faculdade Cearense em Revista, v. 6, n. 2, p. 1-12, 2012.

SRINVASAN, R.; LOHITH, C. P.; KADADEVARAMTH; R. S.; S. SHRISHA. Strategic Marketing and Innovation Performance of Indian MSMEs. Proceedings of PICMET '15: Management of the Technology Age, p. 127-133, 2015.

STAKE. R. E. Case studies. In: DENZIN, N. K.; LINCOLN, Y. S. (ed.) Handbook of qualitative research. London: Sage, 2000.

VARADARAJAN, R. Strategic Marketing and marketing strategy. In: SHANKAR, V.; CARPENTER, G. S. (Eds.). Handbook of Marketing Strategy. Cheltenham, UK: Edward Elgar Publishing Limited, 2012.

VIEIRA, M. M. F. Por uma boa pesquisa (qualitativa) em administração. In: VIEIRA, M. M. F.; ZOUAIN, D. M. (Org.). Pesquisa qualitativa em administração. 2 ed. Rio de Janeiro: Editora FGV, 2006. p. 13-28. 